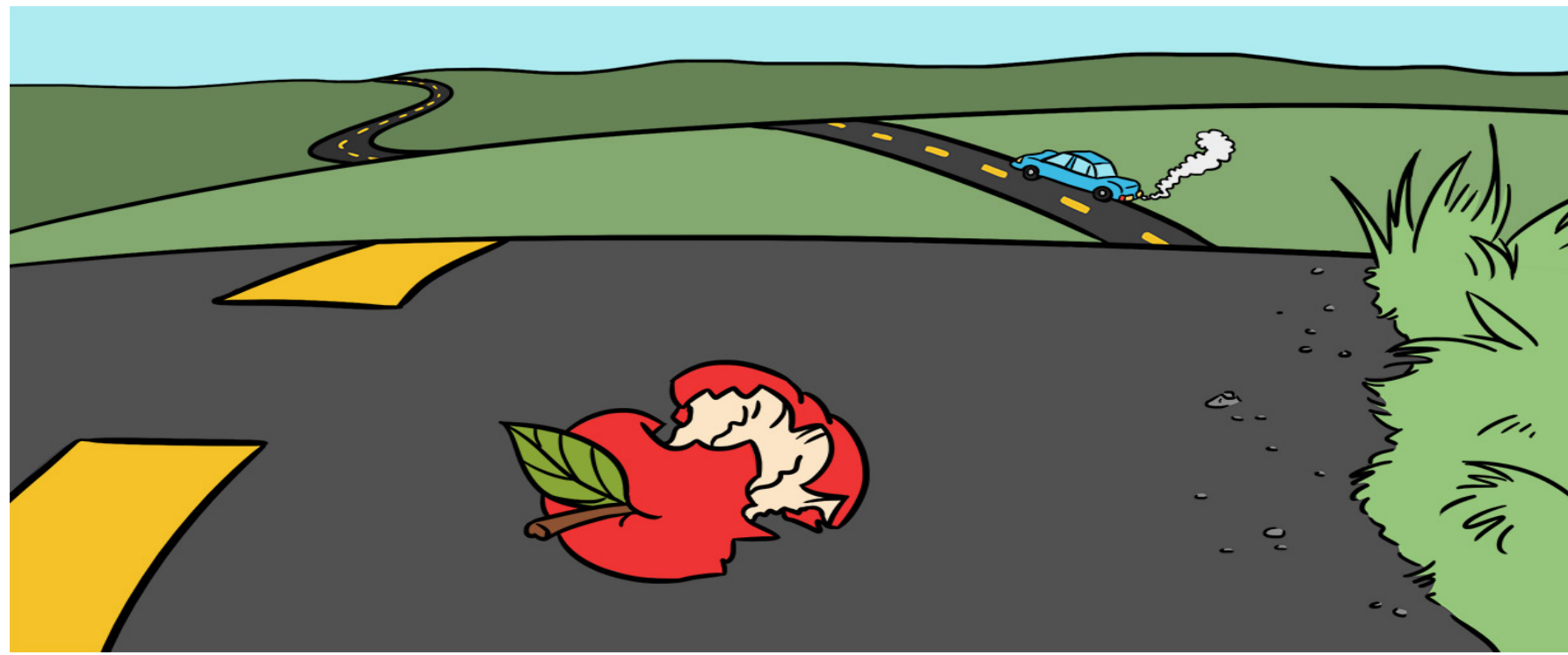

\title{
IS THROWING AN APPLE CORE OUT OF THE CAR LITTERING? -MICROBIAL COMMUNITIES IN NATURAL COMPOSTING
}

\section{Michaeline B. N. Albright* and Jennifer B. H. Martiny}

Department of Ecology and Evolutionary Biology, University of California Irvine, Irvine, CA, United States

\section{REVIEWED BY: \\ PIETRO AGE: 14}

DECOMPOSITION

The process by which compounds such as plant materials, which are made of complex carbon, are broken down into simpler forms of carbon; also called decay or rotting.
Have you ever thrown an apple core or an orange peel out of the car window? Is this littering? What happens if it lands on the pavement? Is it the same as if it lands in a patch of soil on the side of the road? Apple cores, orange peels, leaves, and other plant materials are made up of complex carbon compounds, which get broken down over time into simpler forms of carbon in a process called decomposition. Decomposition is a key part of the carbon cycle. And decomposition is largely done by microbial communities, groups of tiny living organisms, invisible cities that live everywhere on Earth. Can you imagine these invisible cities, eating the apple core that you threw away or a pile of leaves on the ground? How quickly do the dead plants decompose? And where is the carbon going?

\section{WHAT IS DECOMPOSITION?}

Composting, creating a pile or bin of food scraps and yard clippings and allowing this waste to decompose to create soil, is one example of decomposition. 


\section{CARBON CYCLE}

A series of processes by which carbon compounds change form in the environment. Two key components include uptake of carbon dioxide $\left(\mathrm{CO}_{2}\right)$ from the

atmosphere by plants and return of carbon $(\mathrm{C})$ to the atmosphere during decomposition.

\section{NUTRIENTS}

Substances that provide the nourishment needed for growth and life.

\section{MICROBIAL}

\section{COMMUNITIES}

Groups of microorganisms (life forms often too small to see), such as bacteria and fungi, that share a common living space.

\section{FIGURE 1}

Microbial communities live on dead plant leaves and decompose the leaves. As microbes use the carbon from the dead leaves, they release some into the air as $\mathrm{CO}_{2}$ and they store some carbon in the soil. Microbes also release other nutrients, such as nitrogen and phosphorous, from the dead plants, fertilizing the soil. Plants use $\mathrm{CO}_{2}$, water, nutrients, and sunlight to grow. This illustration shows the carbon cycle, and a connection between plants and microbial communities (shown on the leaves).
Decomposition is the process by which compounds such as plant tissue, which are made of complex carbon, are broken down into simpler forms of carbon. The element carbon (C) is the basis of all life on Earth and is part of the ocean, air, rocks, and even us. Carbon moves between different forms through the carbon cycle. In the atmosphere, carbon is attached to oxygen and makes a gas called carbon dioxide $\left(\mathrm{CO}_{2}\right)$. Plants use $\mathrm{CO}_{2}$, water, nutrients, and sunlight to grow. The carbon is incorporated into the plants in the form of complex compounds. Eventually, plants die and decompose. As part of the decomposition process, some of carbon is released into the air as $\mathrm{CO}_{2}$ and some of the carbon is stored in the soil. Other nutrients, such as nitrogen and phosphorous, are also released from the dead plants, fertilizing the soil (Figure 1).

\section{DO YOU KNOW HOW DEAD PLANTS DECOMPOSE?}

Microbes, which are tiny living organisms such as bacteria and fungi, break down plant tissue, using it as food, an energy source. Microbes live on every part of the Earth. When different types of microbes are found together in the same place, scientists refer to them as microbial communities. These communities, even though they are made up of millions of individual microbes, are so small that we cannot see them; they are like invisible cities living among us. But, just because they are small does not mean that they are not important. Microbial communities are crucial for life on Earth. One of the important roles of microbial communities is to decompose dead plants and animals, in order to help to move carbon through the carbon cycle and release nutrients into the soil (Figure 1). As microbes use the carbon from the dead plants, they release some into the air as $\mathrm{CO}_{2}$ and they store some carbon in the soil. This soil carbon takes many forms. For example, some carbon is incorporated into microbial cells as they grow, and some carbon helps to form new soil particles or attaches to older soil particles.

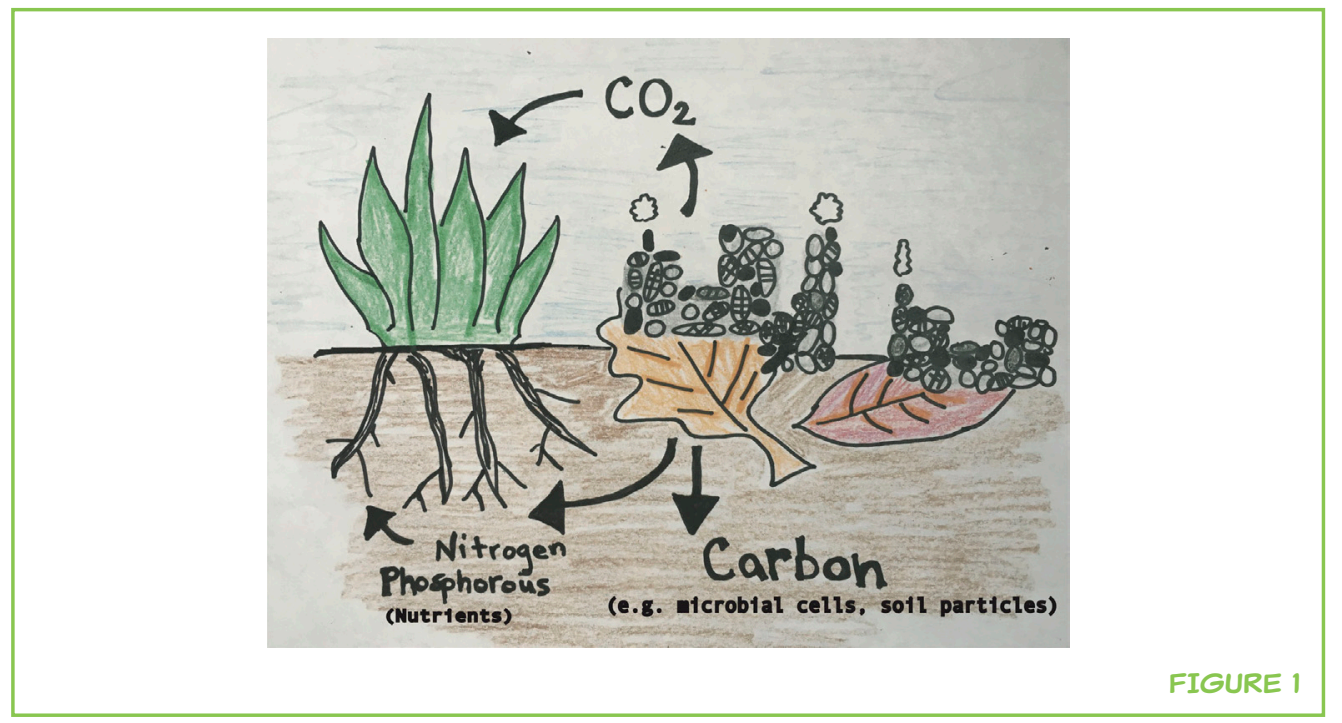




\section{MASS}

A measurement of the amount of matter something contains. On Earth, mass and weight are the same, but on the moon, where gravity is different, an object would have the same mass as on earth but a different weight.

\section{LITTERBAG}

A container, usually made of cloth or mesh and filled with plant material, that scientists use to measure changes in the weight of the plant material over time (decomposition rate).

\section{FIGURE 2}

Litterbags in the field at two different locations.

The litterbags (white squares) are constructed from nylon material using duct tape and glue. The litterbags are then placed into wire cages and staked into the ground so that animals (like squirrels or mice) do not disturb them. Litterbags are tagged to keep track of the individual samples. Each location has multiple litterbags which are experimental replicates. Photo credit: Alexander Chase.
Composting speeds up the natural process of decomposition by creating conditions that allow the microbial communities to work extra efficiently. But decomposition does not only happen in compost, it is essential in the natural environment as well. What happens when leaves fall off trees? Well, in your yard, you might rake them up and jump in them. But what if you did not? They would not just pile up higher and higher year after year. They would eventually be decomposed by microbes, just like the material in a compost pile.

\section{HOW DO SCIENTISTS MEASURE DECOMPOSITION?}

While we cannot see decomposition as it occurs, we can measure its effects by weighing decomposing material to see how much mass is lost over time. Tools that scientists often use to measure the decomposition of plants are called litterbags (Figure 2). Litterbags are containers that are constructed out of mesh, a material that is permeable enough to let water, air, and nutrients through. Litterbags are filled with plant material, weighed, left outside in the field for some amount of time, and then collected and re-weighed. The amount of mass lost can be used to calculate a decomposition rate (mass loss per time). The decomposition rate tells us how quickly or slowly material is being decomposed. Litterbags allow scientists to test which factors affect decomposition rates in an ecosystem. The factors scientists are interested in testing include the amount of moisture present, soil $\mathrm{pH}$, the types of plants

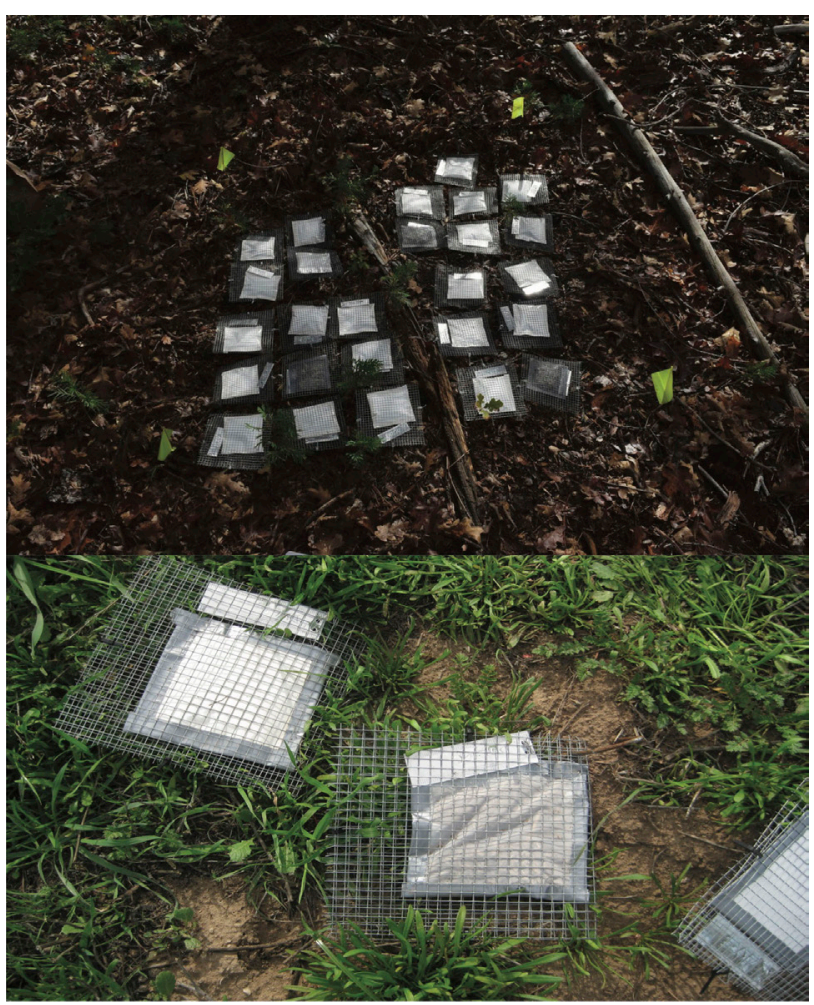

FIGURE 2 
MICROBIAL

\section{DIVERSITY}

Variety and variability in the abundance and types of microorganisms.

\section{FIGURE 3}

A. A field experiment set up to test how differences in microbial diversity (microbial communities originally collected from a dry versus wet grassland environment) affect decomposition rates. The white boxes represent litterbags. The litterbags all have the same type of dead plants inside of them. However, each litterbag contains only one of two different microbial communities (represented by the black and gray shapes - "invisible cities"). One microbial community was originally collected from a dry environment (sun) and the other microbial community was originally collected from a wet environment (rain).

There are three replicate litterbags for each type of microbial community. The litterbags are all placed in one location together in the field. B. Decomposition rate is measured by weighing litterbags before placing them in the field and then weighing them again at the end at a later time to see how much of the dead plant mass in the litterbags is lost during that time. The litterbags shown in panel $(A)$ were weighed at the beginning of the experiment, they were placed in the field for a year and then they were collected and weighed again. The percent (\%) mass loss is the percent change in weight from the beginning to the end of the experiment [(initial that are decomposing, and microbial diversity, which means the different types and numbers of microbes present in the soil $[1,2]$.

\section{DO DIFFERENT MICROBIAL COMMUNITIES DECOMPOSE PLANT MATERIAL MORE SLOWLY OR QUICKLY?}

One example that showed the importance of microbes in decomposition was an accidental experiment, the Chernobyl disaster, a catastrophic nuclear accident that occurred in 1986 in what is now Ukraine. The accident released massive amounts of radioactive material from a nuclear plant, impacting humans and the environment. In terms of the microbes, the accident sterilized the soil, killing the microbial communities. Almost 30 years later, the site of this accident has accumulated tall piles of fallen leaves and many dead trees; the dead plant material is not decaying. When scientists conducted litterbag experiments to determine why, they found that the really slow decomposition was mostly due to the lack of microbes [3].

Scientists can set up field experiments when they have questions they want to answer. For example, how will climate change impact decomposition rates? In one study, to answer this question, researchers added different microbial communities, one from a dry grassland environment and one from a wet grassland environment, to litterbags containing sterilized grassland plant material [2] (Figure 3A). These litterbags were made out of mesh with really, really small holes, to make a cage for the microbes so they could not get in or out. The litterbags were weighed and then placed outside in a grassland

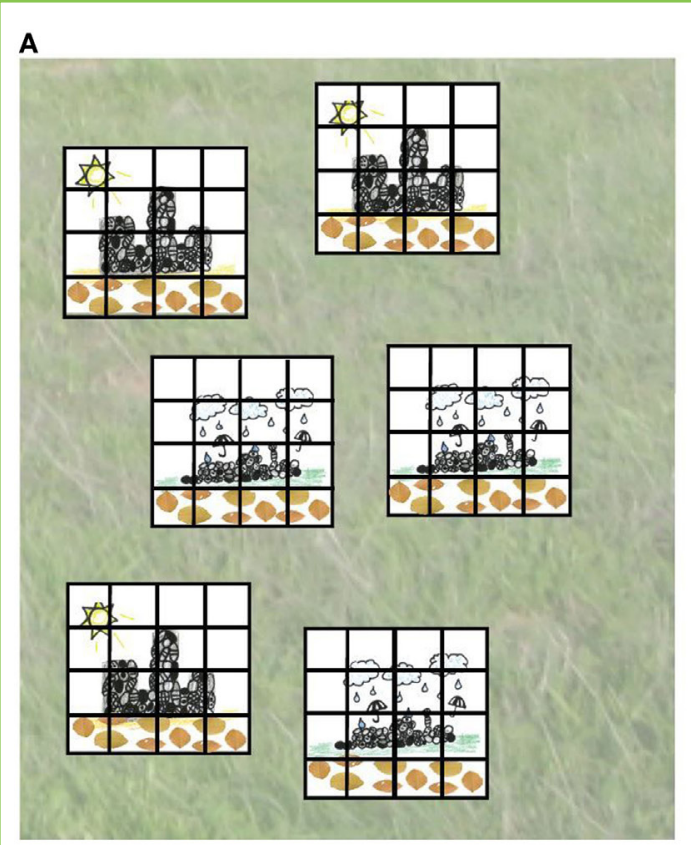

B

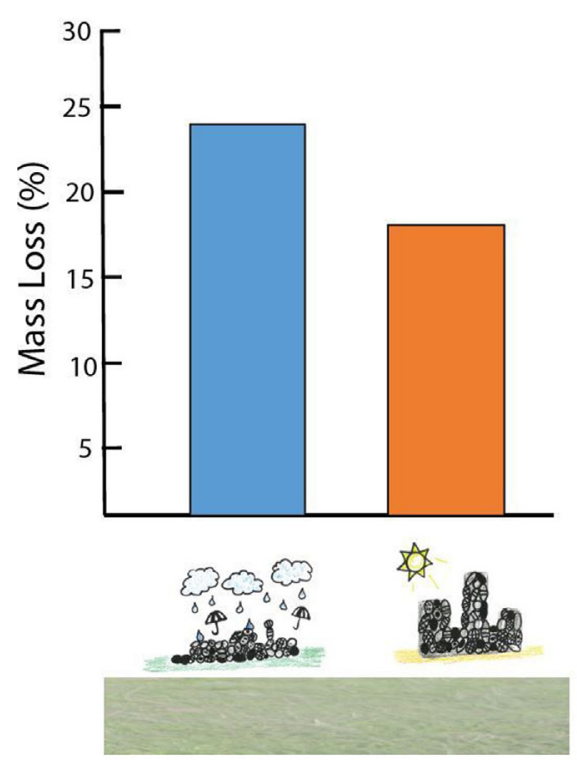

FIGURE 3 
FIGURE 3

\section{CONTINUED}

mass - final mass)/initial mass * $100 \%]$, or in other words how much plant material was decomposed. These data show that the microbial communities that were originally from the wet environment (blue bar) decomposed more of the dead plant material than the microbial communities originally from the dry environment (orange bar) (adapted from Allison et al. [2]). and collected after many months. The researchers found that the litterbags containing the microbial communities from the dry conditions had slower decomposition rates than those from the wetter conditions, even though the litterbags were placed in the same environment during the experiment (Figure 3B). This example shows that the kinds of microorganisms that are present in the community influence the rate of decomposition. The researchers hypothesized that the microbial community from the dry environment worked slower, because those microbes were specialized for surviving in harsher conditions, while the microbes from the wet environment were better at decomposing dead plants more quickly. More experiments are continuing to test this hypothesis.

\section{WHY ARE SCIENTISTS INTERESTED IN LEARNING MORE ABOUT DECOMPOSITION?}

Decomposition is part of nature's recycling process. It is not just an ending, but also a beginning. It is part of the global carbon cycle, which is critical to life on Earth. For plant material in particular, in natural ecosystems, researchers want to know how decomposition affects soil quality and how decomposition might change with a changing climate. Will warmer temperatures speed up decomposition, putting more $\mathrm{CO}_{2}$ into the atmosphere? Maybe, but microbial communities might not work as quickly in warmer climates, or they might switch what they like to eat. Many complex pieces work together to drive the decomposition process and we do not yet know how they all work together.

Decomposition has many other important functions. Decomposition is a key to better fuels made from plant materials. In order to use agricultural crops, such as corn or soybeans, for fuel, scientists need to figure out how to break down plant material more efficiently. One possible solution is figuring out which microbes or microbial communities might do the job [4]. And decomposition happens inside of us. Microbial communities that are living in the gut help us to decompose and digest the food that we eat [5]. There remains a lot to be learned about how these microbial communities affect us and our health.

\section{HOW CAN YOU LEARN MORE ABOUT DECOMPOSITION?}

Guess what? You can experiment with decomposition, too! The starting tools are as simple as a piece of cloth and glue to construct litterbags, plant material, and a scale to measure changes in weight over time. What is your question? What factors do you want to investigate? Or, the next time you are about to throw something out your car window, think about this question: how quickly will it decompose? If it lands in a patch of soil, which could have high microbial diversity, it might decompose faster than if it lands on the pavement, where 
the microbial diversity is probably lower. And if the thing that you throw out is something that is easier for microbes to eat, like an apple core, decomposition might be faster than if you throw out something harder to break down, like an orange peel. But either way, what you throw out might still take months to decompose. You can even start exploring decomposition by making a compost pile with kitchen vegetable scraps and grass clippings and watch as it turns into soil. Yay for decay!

\section{ACKNOWLEDGMENTS}

Thank you to Sara Ludovise, Kaitlin Magliano, and Crystal Cove Alliance for their partnership in translating microbial ecology to schoolchildren and the broader public. Thank you to Jessica Pratt for comments on earlier versions of this article. This work was supported by the US Department of Education Graduate Assistance in Areas of National Need Program, the US Department of Energy and the National Science Foundation.

\section{REFERENCES}

1. Couteaux, M. M., Bottner, P., and Berg, B. 1995. Litter decomposition, climate and liter quality. Trends Ecol. Evol. 10, 63-66. doi:10.1016/S0169-5347(00)88978-8

2. Allison, S. D., Lu, Y., Weihe, C., Goulden, M. L., Martiny, A. C., Treseder, K. K., et al. 2013. Microbial abundance and composition influence litter decomposition response to environmental change. Ecology 94, 714-725. doi:10.1890/12-1243.1

3. Mousseau, T. A., Milinevsky, G., Kenney-Hunt, J., and Moller, A. P. 2014. Highly reduced mass loss rates and increased litter layer in radioactively contaminated areas. Oecologia 175, 429-437. doi:10.1007/s00442-014-2908-8

4. Rubin, E. M. 2008. Genomics of cellulosic biofuels. Nature 454, 841-845. doi:10.1038/nature07190

5. Gill, S. R., Pop, M., Deboy, R. T., Eckburg, P. B., Turnbaugh, P. J., Samuel, B. S., et al. 2006. Metagenomic analysis of the human distal gut microbiome. Science 312, 1355-1359. doi:10.1126/science.1124234

SUBMITTED: 29 April 2017; ACCEPTED: 01 March 2018; PUBLISHED ONLINE: 22 March 2018.

EDITED BY: Gianpiero Vigani, Università degli Studi di Torino, Italy

CITATION: Albright MBN and Martiny JBH (2018) Is Throwing an Apple Core Out of the Car Littering?-Microbial Communities in Natural Composting Front. Young Minds 6:13. doi:10.3389/frym.2018.00013

CONFLICT OF INTEREST STATEMENT: The authors declare that the research was conducted in the absence of any commercial or financial relationships that could be construed as a potential conflict of interest. 


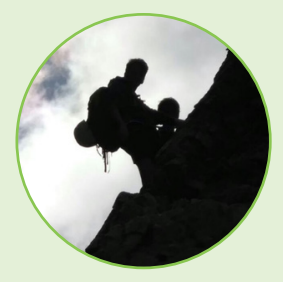

COPYRIGHT () 2018 Albright and Martiny. This is an open-access article distributed under the terms of the Creative Commons Attribution License (CC BY). The use, distribution or reproduction in other forums is permitted, provided the original author(s) and the copyright owner are credited and that the original publication in this journal is cited, in accordance with accepted academic practice. No use, distribution or reproduction is permitted which does not comply with these terms.

\section{REVIEWED BY}

\section{PIETRO, AGE: 14}

Born 13 years after 1990, Pietro lives in Milan. He attended the elementary school "Casa del Sole," a wonderful school in a big park, and the middle school Q. Di Vona. He loves reading, especially when he should do something else (for example help setting the table for dinner or study), postponing homeworks too when he is tired and, first of all, eating. He is also fond of maths and physics, so he would be glad to review some articles about these topics.

\section{AUTHORS}

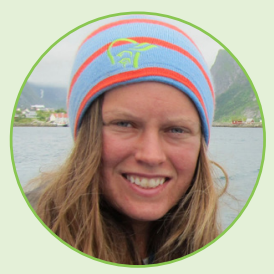

\section{MICHAELINE B. N. ALBRIGHT}

I first became intrigued by microbes when I learned about their amazing metabolic diversity. Different types of microbes can eat everything from dead plants to toxic metals! My research focuses on the connections between microbial diversity and biogeochemical cycling, which is the movement and transformations of carbon and other nutrients through different places on Earth. *nelsonmb@uci.edu

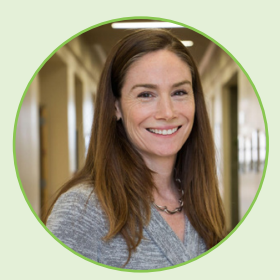

\section{JENNIFER B. H. MARTINY}

I became an ecologist because I was fascinated by understanding why species diversity varies among different kinds of ecosystems - and I wanted to work outside in beautiful places! I first studied the diversity of plants and animals, but then I realized that I had been ignoring most of the biodiversity on the planet: the microorganisms. Now my lab studies how microbial diversity varies in different places and what that means for the plants, the animals, and the ecosystem. 